\title{
Synergistic effects of inhibiting the MNK-eIF4E and PI3K/AKT/ mTOR pathways on cell migration in MDA-MB-231 cells
}

\author{
Ella Lineham¹, Graham J. Tizzard², Simon J. Coles², John Spencer ${ }^{3}$ and Simon J. \\ Morley ${ }^{1}$ \\ ${ }^{1}$ Department of Biochemistry, School of Life Sciences, University of Sussex, Falmer, Brighton, UK \\ ${ }^{2}$ UK National Crystallography Service, School of Chemistry, University of Southampton, Highfield, Southampton, UK \\ ${ }^{3}$ Department of Chemistry, School of Life Sciences, University of Sussex, Falmer, Brighton, UK \\ Correspondence to: Simon J. Morley, email: s.j.morley@sussex.ac.uk \\ Keywords: cell signaling; migration; kinase; dual inhibitors
}

Received: December 19, 2017 Accepted: January 25, 2018 Epub: January 31, 2018 Published: March 06, 2018

Copyright: Lineham et al. This is an open-access article distributed under the terms of the Creative Commons Attribution License 3.0 (CC BY 3.0), which permits unrestricted use, distribution, and reproduction in any medium, provided the original author and source are credited.

\section{ABSTRACT}

The study of eukaryotic initiation factor 4E (eIF4E) is a key focus in cancer research due to its role in controlling the translation of tumour-associated proteins, that drive an aggressive migratory phenotype. eIF4E is a limiting component of the eIF4F complex which is a critical determinant for the translation of mRNAs. Mitogenactivated protein kinase interacting protein kinases (MNK1/2) phosphorylate eIF4E on Ser209, promoting the expression of oncogenic proteins, whereas mTORC1 phosphorylates and de-activates the eIF4E inhibitor, 4E-BP1, to release translational repression. Here we show that inhibiting these pathways simultaneously effectively slows the rate of cell migration in breast cancer cells. However, a molecular hybridisation approach using novel, cleavable dual MNK1/2 and PI3K/mTOR inhibiting hybrid agents was less effective at slowing cell migration.

\section{INTRODUCTION}

Metastasis of cancer cells and the formation of malignant secondary tumours is extremely problematic in the clinic, accounting for approximately $90 \%$ of human cancer deaths [1]. Cancer cells require elevated protein synthesis to invoke this invasive phenotype, which has the ability to bypass tissue barriers, intravasate into the bloodstream and seed at distal secondary sites [2]. This is particularly apparent in Triple-Negative Breast Cancer (TNBC), a rapidly spreading, primary breast cancer that has poor prognosis and limited treatment options [3].

MAPK-interacting kinases (MNKs) are serine/ threonine kinases that lie downstream of essential signaling pathways, and are commonly amplified in cancer cells [4]. Each MNK gene, MKNK1 and MKNK2, produces a long and a short isoform through variation in splicing $[5,6]$. The longer isoforms (MNK1a and MNK2a) contain a MAPK binding site, which is lacking in the shorter isoforms (MNK1b and MNK2b) [5, 6]. The MNKs differ in their regulation; MNK1a has low basal activity, and is activated and tightly regulated by ERK and p38 kinases in response to mitogens and stress [7, 8]. MNK2 displays high basal activity and is predominantly regulated by ERK1/2, although MNK2a is regulated by mTORC1 through at least one site in its C-terminal region $[9,10]$.

The eukaryotic translation initiation factor $4 \mathrm{E}$ (eIF4E) is the rate-limiting component of the eIF4F complex, essential for cap-dependent translation. Its availability is regulated by $\mathrm{mTORC} 1$, through the phosphorylation of 4E-binding protein 1 (4E-BP1). MNK1/2 phosphorylate S209 of eIF4E, promoting the expression of oncogenic proteins. Phosphorylated eIF4E (eIF4E-P) preferentially enhances the translation of a subset of mRNAs involved in cell survival. These include a number of genes implicated in metastatic and invasive behaviour, such as C-MYC, cyclin D1, PIM1 , survivin, BCL-2, vascular endothelial growth factor 
(VEGF), fibroblast growth factor (FGF-2) and matrix metalloproteinase-9 (MMP9) [11, 12]. This addiction to increased protein synthesis provides a therapeutic window to selectively target the translational machinery of cancer cells $[13,14]$.

MNK1/2 represent an attractive potential therapeutic target as they act at the convergence point of two critical signaling pathways; p38MAPK and ERK, which are often subject to up-regulation in tumour cells [4, 15-17]. MNK1/2 knockout mice exhibit total abrogation of eIF4E phosphorylation and display no developmental or reproductive defects $[15,18]$. Furthermore, knock-in mice expressing a mutant form of eIF4E (S209A) are no longer phosphorylated on eIF4E by MNK1/2 and exhibit resistance to neoplastic transformation [19].

There is evidence for a compensatory feedback mechanism linking the PI3K-AKT-mTOR and the MNKeIF4E pathways. In prostate and lung cancer, downregulation of one pathway correlated with the activation of the other, which subsequently promoted cell growth and cancer survival $[18,20]$. Dual inhibition of MNK1/2 kinase and mTORC1 suppressed cell cycle progression and blocked proliferation in both prostate and glioblastoma cell lines. This effect was increasingly pronounced when inhibitors were added in combination, indicating the importance of dual abrogation of such pathways $[18,20]$. Recently published work also found that increased levels of eIF4E-P was a common feature in breast cancer patient response to chemotherapy and was associated with poor clinical outcome. Treatment with MNK1/2 inhibitors sensitised breast cancer cells to chemotherapy in vivo and resulted in an enhanced response to treatment [21].

The heterogeneous nature of cancer and complexity of cellular signalling means that the traditional single treatment approach is often ineffective. Inhibition of multiple targets is required to outsmart the tumour cell [13, $22,23]$. This has led to the concept of hybrid drugs, which involves the linking of two selected pharmacophores that act against different therapeutic intracellular targets simultaneously. This multi-hit approach may lead to an increase in synergy and make drug resistance less likely to occur [18].

There are no FDA approved drugs that specifically act on MNK1/2. The pyrazolo-pyrimidine compound CGP57380 exhibits low micromolar MNK1 inhibition and cercosporamide, a natural anti-fungal agent, was found to be a potent inhibitor of MNK1/2 [4, 7, 9, 11, 14, 15, 17]. However, the broad spectrum effects of cercosporamide limit its uses as an effective treatment [4, 24, 25]. Due to our interest in developing a hybrid therapy we sought to identify a MNK1/2 inhibitor with the characteristics to facilitate the development of such agents. A potent MNK1/2 inhibitor, 1, has recently been synthesised, which is relatively selective compare with current inhibitors [26].

In this study, we examined the effect of dual inhibition of MNK-eIF4E and PI3K-AKT-mTOR pathways (Figure 1) on cell migration, cell viability and cell cycle arrest. These data led to the attempted development of dual action MNK hybrid agents, with a view to simultaneously inhibit these pathways.

\section{RESULTS}

\section{The effect of dual-inhibition of both eIF4E-MNK and PI3K-AKT-mTOR pathways on downstream signalling molecules in MRC5 cells}

MNK1/2 phosphorylate eIF4E on S209, enhancing the translation of specific mRNAs involved in cell survival and metastasis. MNK1/2 kinases are an attractive therapeutic target as they are dispensable during normal development and hence could be used to selectively kill cancer cells [26]. In our study, highly migratory MRC5 lung fibroblasts and MDA-MB-231 breast cancer cells (wildtype PI3K and BRCA1, mutated KRas (G13D) [28] and mutated P53 (missense mutation) [29]) were both used to probe the response of dual-inhibition of the eIF4E-MNK pathway and PI3K-AKT-mTOR pathways (Figure 1). Compound 1 (Figure 2), was found to be a potent $\mathrm{MNK} 1 / 2$ inhibitor in the nanomolar range in cell-free kinase assays [30]. In our hands, Compound 1 reduced the level of eIF4E phosphorylation in a concentration-and time-dependent manner, being effective at concentrations above $1 \mu \mathrm{M}$ for 4 hours or longer (Figure $3 \mathrm{~A}$ and 3B). In contrast, CGP57380 (Figure 3A, lane 8) and staurosporine (Figure 3A, lane 9) had no effect on eIF4E-P under these assay conditions. The inhibition of $\mathrm{MNK} 1 / 2$ did not affect the upstream activation of MNK1/2, or lead to an increase in cell stress, as observed by the constant level of AMPK T172 phosphorylation in relation to the DMSO control. Increased incubation time with 1 for 16 hours and above, resulted in partial inhibition of 4E-BP1 phosphorylation, as depicted by an increase in the level of the less-phosphorylated form of 4E-BP1 upon Western blotting (Figure 3A and 3B).

To assess the significance of simultaneous MNK1/2 and PI3K inhibition, an effective PI3K p110 $\alpha$ inhibitor, 3-[4-(4-morpholinyl)thieno[pyrimidin-2-yl]phenol, 2, [31], was used to observe the effect on various signalling molecules (Figure 2 and Figure 3C). The efficacy of 2 as a PI3K inhibitor was measured by monitoring the inhibition of phosphorylation of AKT-T308. This phosphorylation is $\mathrm{PI} 3 \mathrm{~K}$-dependent, resulting from the conversion of PIP2 to PIP3 and the activation of PDK1 [32]. Molecule 2 was found to inhibit AKT-T308 phosphorylation at concentrations greater than $100 \mathrm{nM}$ in MRC5 cells. The observed effect of 2 on mTOR signalling was also as predicted, with mTORC1 substrates, 4E-BP1, p70S6K and consequently ribosomal protein $\mathrm{S} 6$ phosphorylation inhibited in a dose-dependent manner (Figure 3C). This is explained by the shared sequence similarity in the C-terminal kinase domain of both mTOR and PI3K [33]. 
Interestingly, 2 appeared to reduce the level of eIF4E-P at high concentrations, suggesting an overlapping function in the eIF4E-MNK pathway. The phosphorylation of eIF4E was abolished when 2 was used in combination with 1 .

When monitored by Western blotting, the level of eIF4E protein remained constant throughout the drugtreated cells. A low level of cleaved PARP was observed when 2 was used at high concentrations alone or in combination with 1 (Figure 3C), indicating apoptosis at elevated final concentrations.
In addition to targeting the PI3K pathway at the level of PI3K, we used the pyrimidine derivative, PP242 (torkinib), to inhibit this pathway. PP242 has an $\mathrm{IC}_{50}$ of $8 \mathrm{nM}$ in cell-free assays and selectively targets both mTORC1 and mTORC2 complexes over PI3K isoforms [34] (Figure 1). Consistent with published data [34], PP242 at a $1 \mu \mathrm{M}$ final concentration inhibited the phosphorylation of 4E-BP1 (Figure 3D and 3E) as well as other targets downstream of mTORC1, including p70S6K and ribosomal protein S6 (data not shown).

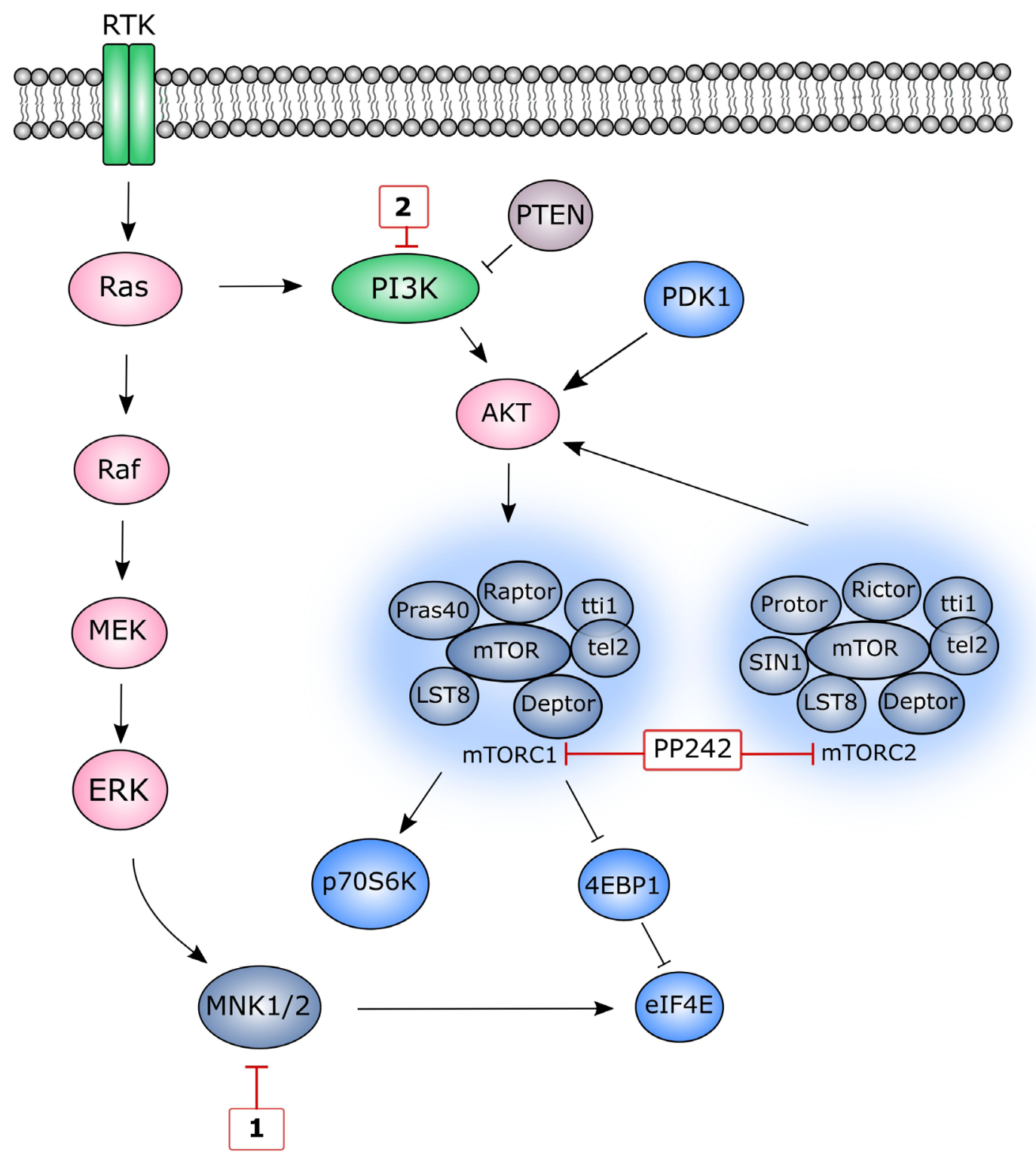

Figure 1: A simplified schematic representation of MNK1/ 2 and mTOR pathways. Red boxes depict several inhibitors of specific pathway components used in this study. MNK1/2 lie at the convergence point of both the p38MAPK pathway and ERK pathways and upon activation, phosphorylate eIF4E. Class I PI3 kinases are activated by RTKs resulting in the conversion of PIP2 to PIP3, a secondary messenger that is essential for AKT translocation to the plasma membrane. The level of PIP3 is negatively regulated by the tumour suppressor, PTEN. AKT is partially activated by PDK1 and becomes fully activated upon phosphorylation at Ser473, a process that can be catalysed by multiple proteins. mTOR forms two distinct multiprotein complexes, mTORC1 and mTORC2. mTORC1 is activated indirectly through AKT. Activated mTORC1 stimulates protein translation by phosphorylating 4E-BP1 on several residues, releasing eIF4E allowing it to participate in translation initiation. In addition to phosphorylating other translational targets, mTORC1 also phosphorylates p70S6 kinase (p70S6K), which becomes fully activated following PDK1-mediated phosphorylation. 
There was a low level of cell death in cells exposed to the 1/ PP242 combination, with more cleaved PARP observed at the highest concentration of $1(10 \mu \mathrm{M}$; lane 2). Incubation of cells with PP242 at $1 \mu \mathrm{M}$ concentration in combination with various concentrations of 1 did not affect the efficacy of the latter on eIF4E-P. The level of ERK-P appeared to be unaffected under all of the conditions tested.

\section{Inhibition of MNK1/2 and the PI3K-AKT- mTOR pathway slows the rate of migration in MDA-MB-231 cells}

The phosphorylation of eIF4E correlates with an increase in levels of mesenchymal markers such as $\mathrm{N}$-cadherin, fibronectin and vimentin, along with the acquisition of invasive properties [35]. Disrupting cellular migration is a promising therapeutic option for the treatment of cancer [36]. Here, we assessed the rate of migration of a breast cancer cell line using real-time monitoring of cell migration. MDA-MB-231 cells were analysed in the presence of various inhibitors alone or in combination as they moved towards a chemo-attractant. Cell migration kinetics were recorded on a RTCA DP instrument for 12 hours. As shown in Figure 4A and 4B, when cells were treated with a combination of 1 and 2 (both at $1 \mu \mathrm{M}$ final concentration), a substantial reduction in cell migration was observed relative to the DMSO control. In comparison, when used as single agents, both 1 and 2 had negligible effects on cell migration. Cell viability data demonstrated that the $\mathrm{MNK} 1 / 2$ inhibitor, 1 , exhibited minimal cytotoxicity at $1 \mu \mathrm{M}$ in MDA-MB-231 cells (Figure 4E and 4F). The PI3K inhibitor, 2, reduced cell viability to $75 \%$, when used either as a single agent or in combination with 1 .
The synergistic effect of $\mathrm{MNK} 1 / 2$ and PI3K inhibition on cell migration led to the investigation of inhibition of both MNK1/2 and mTORC1/2, using PP242. The latter, impaired cell migration to the greatest extent (Figure 4C), although this could in part be explained by a reduction in cell viability to $60 \%$ seen with this compound (Figure 4F). A combination of 1 with PP242 appeared to rescue the effect of PP242 used alone, with the cell index returning to the level of the DMSO control (Figure 4C). One possible explanation for this reflects a recent publication demonstrating that $\mathrm{MNK}$ forms a complex with mTORC1, promoting mTORC1 association with TELO2 (Phosphatidyl Inositol 3' Kinase-related Kinase (PIKK) stabiliser), which facilitates efficient mTORC1/ substrate binding [37].

The dual inhibition of MNK $1 / 2$ and mTORC1/2 significantly reduced cell viability to $35 \%$ on control levels (Figure 4F), an observation that has been reproduced in several cancer cell lines $[18,20]$. The rescue effect seen when a combination of MNK $1 / 2$ and mTORC1/2 inhibition was used in the cell migration assay suggests only a selected pool of surviving cells were scored in this assay.

\section{The combination of MNK1/2 and $m$ TORC1/2 inhibition induces $G_{1}$ cell cycle arrest in MDA- MB-231 cells}

Next, we investigated whether a combination of $\mathrm{MNK} 1 / 2$ and $\mathrm{PI} 3 \mathrm{~K}$ or $\mathrm{mTORC} 1 / 2$ inhibition was associated with cell cycle arrest in proliferating MDAMB-231 cells over a period of 24 hours. The CDK1 inhibitor, R0-3306, was used as a control for the arrest of cells at the $\mathrm{G}_{2} / \mathrm{M}$ phase border [38]. As demonstrated in Figure 5, each phase of the cell cycle showed a normal
A<smiles>Cc1c(C(=O)O)sc2ncnc(Nc3ccc(F)cc3OC(C)C)c12</smiles>

D<smiles>CC(=O)C1=C(O)C=C2Oc3c(C(N)=O)c(O)cc(O)c3[C@@]2(C)C1=O</smiles>

B<smiles>Oc1cccc(-c2nc(N3CCOCC3)c3sccc3n2)c1</smiles>

E<smiles>Nc1ncnc2[nH]nc(Nc3ccc(F)cc3)c12</smiles>

C<smiles>CC(C)n1nc(-c2cc3cc(O)ccc3[nH]2)c2c(N)ncnc21</smiles>

Figure 2: Inhibitors. (A) Structure of 1, a MNK1/ 2 inhibitor. (B) Structure of 2, a PI3K p110 $\alpha$ inhibitor. (C) Structure of PP242, a mTORC1/2 inhibitor. (D) Structure of cercosporamide, a MNK1/2 inhibitor. (E) Structure of CGP57380, a MNK1/2 inhibitor. 
A

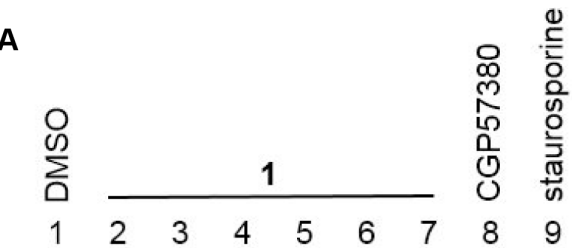

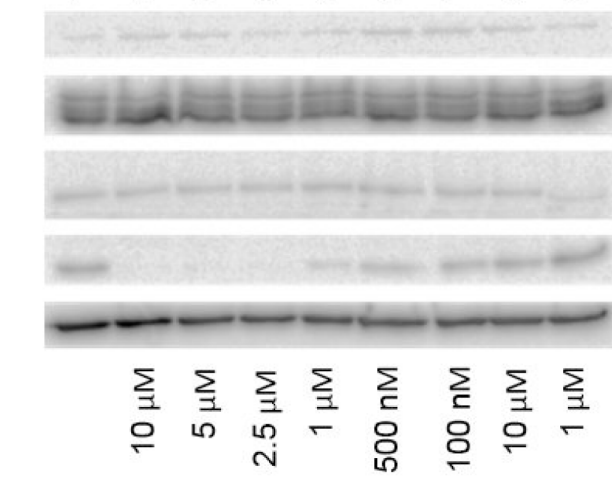

C

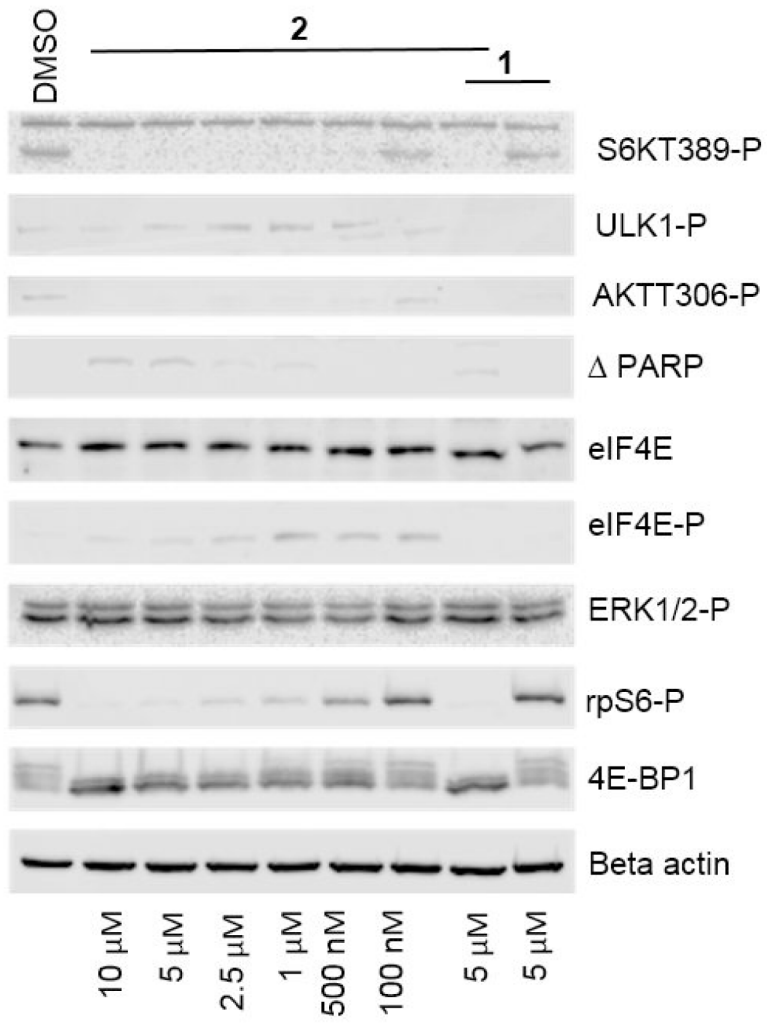

MNK1-P

4E-BP1

elF4E-P

Beta actin
B

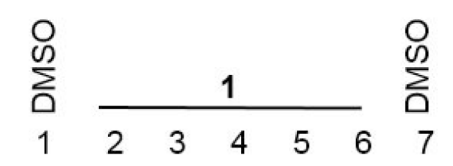

AMPKT172-P

Time (hr)
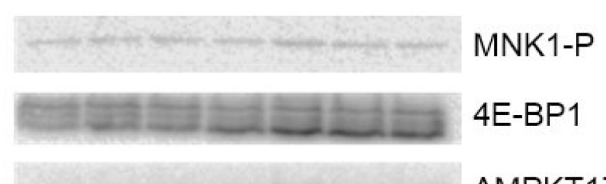

4E-BP1

AMPKT172-P

elF4E-P

Beta actin

D

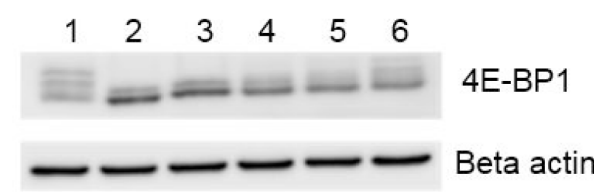

E

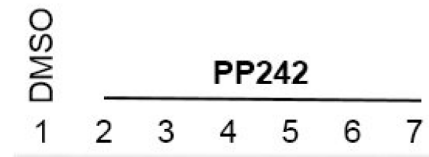

rpS6-P

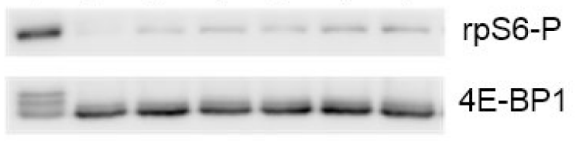

elF4E-P

$\triangle$ PARP

S6KT389-P

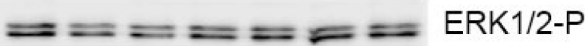

--- Beta actin

Figure 3: Representative Western blot analysis of both the eIF4E-MNK and PI3K-AKT-mTOR pathways in the presence of inhibitors. (A) Western blot analysis showing the effect of different concentrations of 1 on eIF4E-P and various signalling molecules. MRC5 fibroblast cells were incubated with DMSO alone (lane 1) or with the indicated concentrations of inhibitors for 24 hours. Cellular lysates were prepared and immunoblotting was performed using $20 \mu \mathrm{g}$ of total lysate protein, as described in the Materials and Methods. (B) Western blot analysis showing the effect of 1 incubation time on eIF4E-P and various signalling molecules. MRC5 fibroblast cells were incubated with DMSO alone (lane 1) or with $1(5 \mu \mathrm{M})$ for the indicated times. (C) Western blot analysis showing the effect of different concentrations of 2 on AKT-308 phosphorylation and various signalling molecules and the effect of 2 in combination with 1. MRC5 fibroblast cells were incubated with DMSO alone (lane 1) or with the indicated concentrations of inhibitors for 24 hours. (D) Western blot analysis showing the effect of different concentrations of PP242 on 4E-BP1 phosphorylation. MRC5 cells were incubated with DMSO alone (lane 1) or the following final concentrations of PP242: lane 2: $5 \mu \mathrm{M}$, lane 3: 2.5 $\mu \mathrm{M}$, lane 4: $1 \mu \mathrm{M}$, lane 5: $500 \mathrm{nM}$, lane 6: $100 \mathrm{nM}$. (E) Western blot showing the effect of different concentrations of 1 in combination with PP242 $1 \mu \mathrm{M}$. Cells were incubated with DMSO alone (lane 1) or the following final concentrations of inhibitors: lane 2: $110 \mu \mathrm{M}, \mathrm{PP} 2421 \mu \mathrm{M}$, lane 3: $15 \mu \mathrm{M}, \mathrm{PP} 2421 \mu \mathrm{M}$, lane 4: $12.5 \mu \mathrm{M}, \mathrm{PP} 2421 \mu \mathrm{M}$ lane 5: $11 \mu \mathrm{M}$, PP242 $1 \mu \mathrm{M}$, lane 6: $1500 \mathrm{nM}$, PP242 $1 \mu \mathrm{M}$ lane 7: $1100 \mathrm{nM}, \mathrm{PP} 2421 \mu \mathrm{M}$. 
distribution in the DMSO control cells. The MNK1/2 inhibitor, 1, had no effect on cell cycle distribution, whereas both mTORC1/2 and PI3K inhibition, (PP242 and 2 , respectively) increased the number of cells in the $G_{1}$ phase of the cell cycle. However, following exposure to a

A

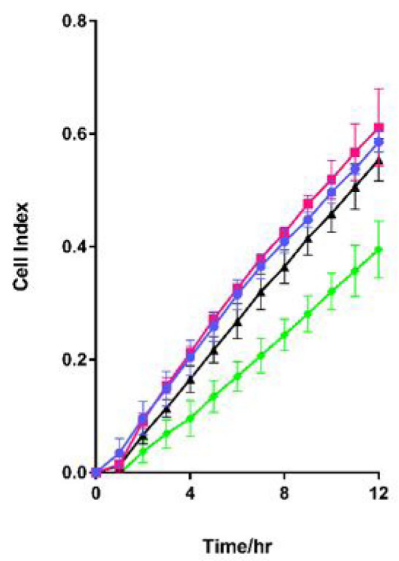

C

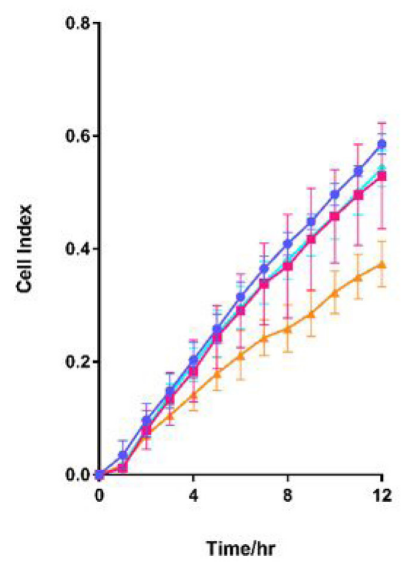

$\mathbf{E}$

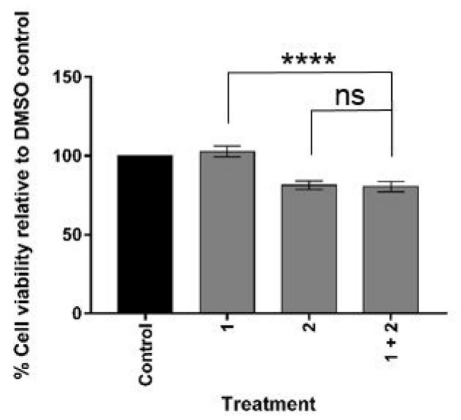

combination of 1 and PP242 at $5 \mu \mathrm{M}$, the number of cells corresponding to the $G_{1}$ phase was increased, while the numbers of cells in the $S$ and $G_{2} / M$ phases were decreased. This combination of inhibitors had a synergistic effect on $\mathrm{G}_{1}$ cell cycle arrest.
B

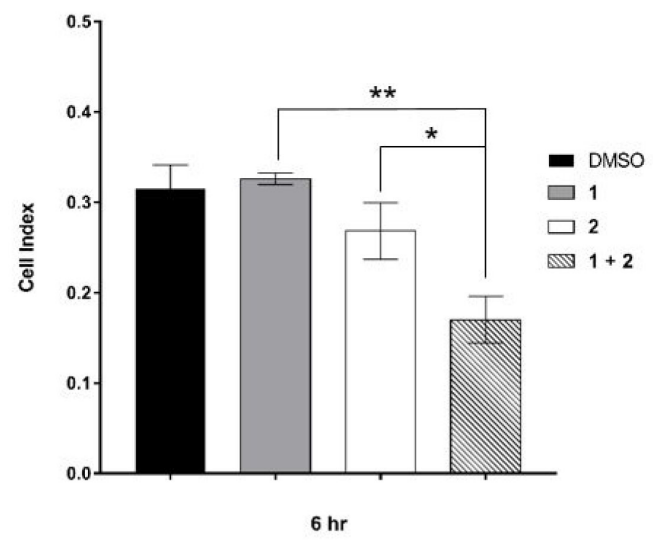

D

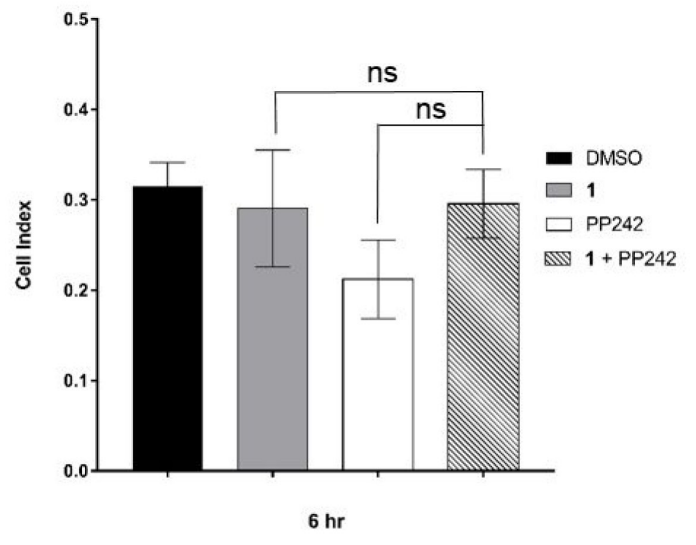

$\mathbf{F}$

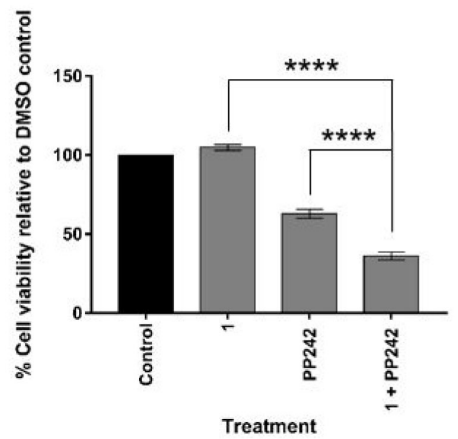

Figure 4: Cell viability and kinetics of migration in drug-treated MDA-MB-231 cells. Cell migration in real time was analysed by the xCELLigence RTCA. (A) and (C) show the cell indexes over 12 hours for each drug treatment at $1 \mu \mathrm{M}$. (B) and (D), cell migration analysis at $6 \mathrm{hr}$. (E) and (F) Viability was assessed by Cell Titer Blue assay. MDA-MB-231 cells were treated for 72 hours with indicated drugs at $1 \mu \mathrm{M}$. Data are mean \pm S.D, $n=3\left({ }^{*} p \leq 0.05{ }^{* *} p \leq 0.01 ;{ }^{* * *} p \leq 0.001\right.$ and $\left.{ }^{* * * *} p \leq 0.0001\right)$. 


\section{Chemistry}

Based upon the observations above and literature precedence, we postulated that a compound containing both MNK1/2 and PI3K/mTOR inhibitory activities might be very effective against cellular migration. A further aim of this work was to synthesise novel hybrid molecules based upon 1 and either PP242 or 2 used in this study. The desired outcome was the development of a novel, single molecular framework incorporating both moieties (Supplementary Experimentals 1, 2 and Supplementary Figure 1). The hybrid concept covers either permanent or prodrug, cleavable dual-action molecules, i) or ii) (Figure $6)$.

The "type ii)" hybrid compounds (6 and 7) were prepared as outlined in Supplementary Scheme 1. Compound 6 was prepared via a simple one-pot synthesis as detailed in the ESI. Compound 7 was prepared by initially converting the carboxylic acid functionality of the starting material, 1 [30] into an acid chloride. This intermediate then underwent an esterification reaction with PP242, leading to the formation of 7 in the presence of base. The final products were fully characterised by HRMS and ${ }^{1} \mathrm{H}$ NMR (Supplementary Experimentals 1, 2 and Supplementary Figure 1). Single crystals of both 6 and 7 were isolated from a chloroform solution and the resulting X-ray analysis is depicted in Figure 7, which showed the expected connectivity i.e. the ester bonds in the products [39].

\section{In vitro analysis of hybrid agents in MRC5 cells}

Compounds 6 and 7 were screened for activity in MRC5 cells by Western blotting (Figure 8A and 8B)
A
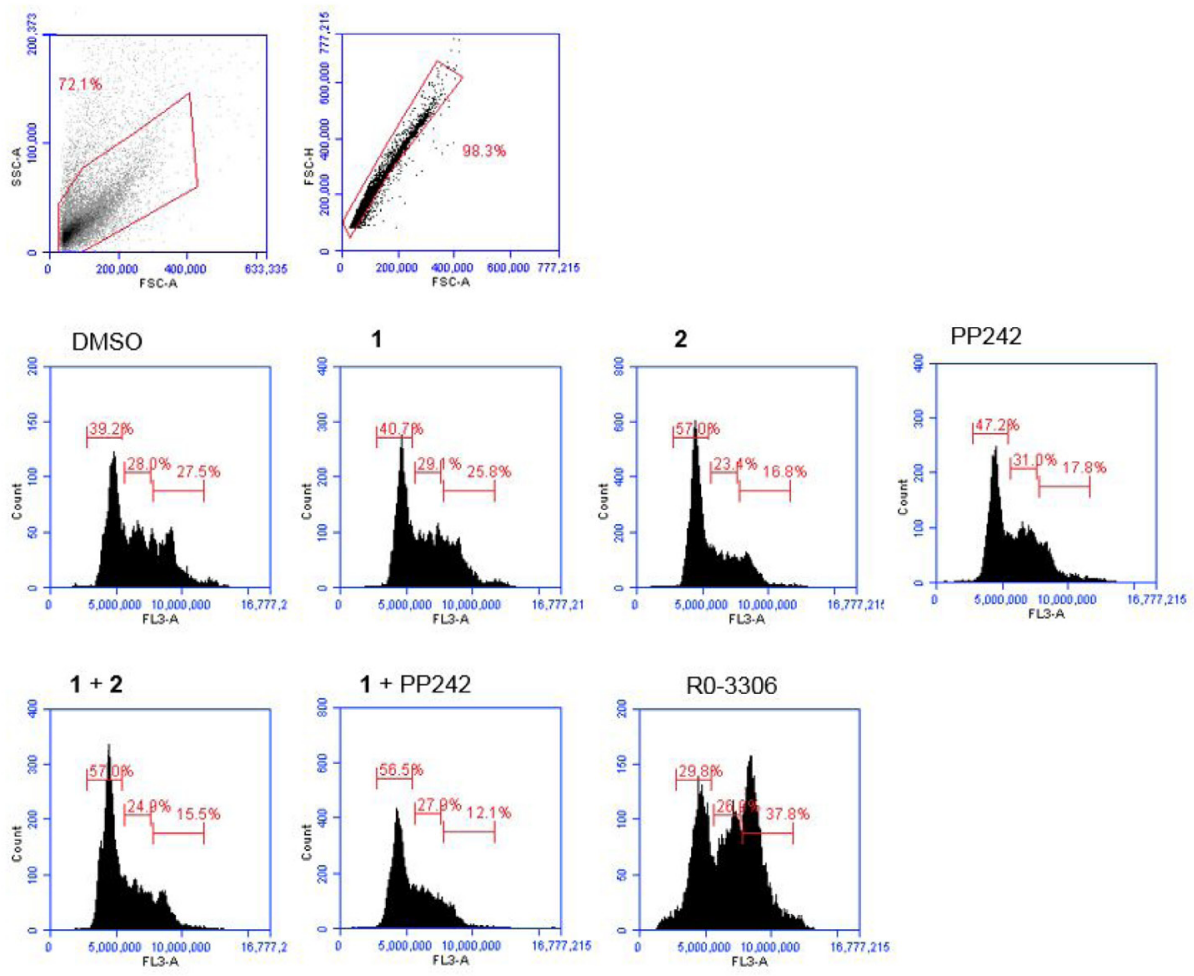

B

\begin{tabular}{|c|c|c|c|}
\hline & $\% \mathbf{G 0} / \mathbf{G 1}$ & $\% \mathrm{~S}$ & $\% \mathbf{G} 2 / \mathbf{M}$ \\
\hline DMSO & $42.0 \pm 3.9$ & $28.8 \pm 1.1$ & $24.7 \pm 3.9$ \\
\hline 1 & $42.4 \pm 2.4$ & $29.3 \pm 0.2$ & $24.2 \pm 2.3$ \\
\hline 2 & $57.4 \pm 0.6$ & $23.8 \pm 0.6$ & $15.9 \pm 1.3$ \\
\hline PP242 & $48.6 \pm 2.0$ & $30.0 \pm 1.4$ & $17.7 \pm 0.2$ \\
\hline $1+2$ & $58.6 \pm 2.3$ & $24.4 \pm 0.8$ & $14.5 \pm 1.5$ \\
\hline $1+\mathrm{PP} 242$ & $54.5 \pm 2.8$ & $28.9 \pm 1.3$ & $13.3 \pm 1.6$ \\
\hline 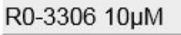 & $33.7 \pm 5.4$ & $28.8 \pm 2.6$ & $32.6 \pm 7.4$ \\
\hline
\end{tabular}

Figure 5: Flow cytometry analysis of the effect of MNKI-19, 191.3 and PP241 both as single agents and in combination $(5 \mu \mathrm{M})$ on cell cycle progression. (A) Representative plots for MDA-MB-231 cells treated for $24 \mathrm{hr}$ with indicated inhibitors at $5 \mu \mathrm{M}$ unless otherwise stated in the data table. (B) Data are mean \pm S.D, $n=2$. 
and compared with known kinase inhibitors, PI-103 and staurosporine. Notably, both 6 and 7 were difficult to solubilise in DMSO and this was reflected in the Western blot analysis. Compound 6 failed to show any noticeable effect on either $\mathrm{PI} 3 \mathrm{~K}$ or $\mathrm{MNK} 1 / 2$ signalling output relative to the controls, represented by little change in AKT-T308-P or eIF4E-P levels, respectively. mTORC1 read-outs, 4E-BP1, S6K T389-P and phospho-ribosomal S6 protein also indicated a lack of inhibition of mTORC1 signalling. In addition, ULK-1-P and AMPK-T172-P were unaffected by the inhibitors used, indicating that cells had not activated a general stress response. When compared to the solvent control, compound 7 slightly reduced the level of eIF4E-P when tested at the highest concentration $(10 \mu \mathrm{M})$. mTORC1 inhibition was observed at the highest concentration, reflected by the collapse of the broad 4E-BP1 signal into a condensed band and a reduction in ribosomal protein S6 phosphorylation. There was a low level of cleaved PARP in cells treated with the 1:1 mixture of 1/ PP242 and in cells treated with compound 7, suggesting that this combination in both forms contributed to cell death. The poor solubility of 6

i)

\section{A-B}

covalently- linked A and B
pharmacophores with mutually
complementary activities

Figure 6: "Permanent" vs. cleavable hybrid approach. and 7 can be explained in part by their physiochemical properties, including high molecular high weight $(>500)$, TPSA $\left(>140 \mathrm{~A}^{2}\right), \log \mathrm{P}(>5)$ (Supplementary Table 1, ESI).

\section{DISCUSSION}

Using MDA-MB-231 cells, we have determined that a synergistic combination of $\mathrm{MNK} 1 / 2$ and $\mathrm{PI} 3 \mathrm{~K}$ inhibitors slowed the rate of cell migration. Additionally, a combination of MNK1/2 and $\mathrm{mTORC1/2}$ inhibitors resulted in cell cycle arrest and a decrease in cell viability to a greater extent in comparison to when the inhibitors were used as single agents. This led to the attempted development of novel hybrid entities, encapsulating MNK1/2 and PI3K/ mTOR inhibitory activities. Although molecular hybridisation approaches hold significant promise, they currently face considerable challenges as therapeutic modalities [40-48]. For example, both 6 and 7 are undoubtedly poorly soluble due to their high molecular weight and lipophilicity. However, simultaneous $\mathrm{MNK} 1 / 2$ and PI3K/mTOR inhibition warrants further investigation as a therapeutic option for treating aggressive migratory cancers [49].

ii)

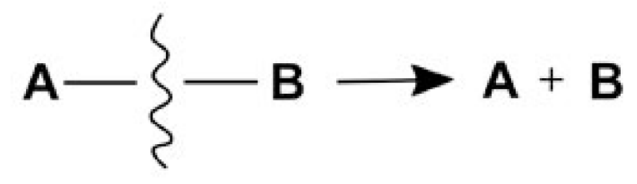

linker is enzymatically cleaved and releases separate pharmacophores
A

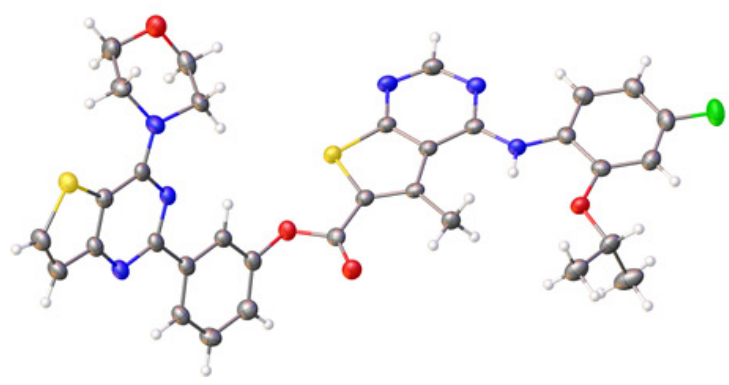

B

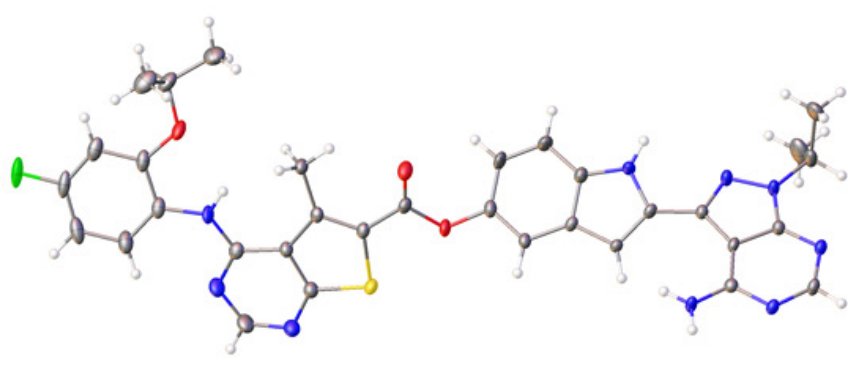

Figure 7: Crystal structures of hybrid agents. (A) Compound 6 (CCDC 1813013), (B) Compound 7 (CCDC 1813012). 


\section{MATERIALS AND METHODS}

\section{Cell culture and cell viability assays}

MRC5 human male foetal lung fibroblasts, SV40 transformed, and MDA-MB-231, human Caucasian female breast adenocarcinoma cells were sourced from the European Collection of Cell Cultures (ECACC) and maintained in Minimal Essential Medium with Glutamax and Earl's salts (MEM, Gibco), supplemented with 10\% $(\mathrm{v} / \mathrm{v})$ foetal bovine serum (FBS, Pan Biotech) at $37^{\circ} \mathrm{C}$ in a humidified atmosphere with $5 \% \mathrm{CO}_{2}$. Cell passage was performed when cells were $70-80 \%$ confluent. Cells were first washed with Dubecco's Phosphate Buffered Saline without calcium chloride or magnesium chloride (DPBS, Sigma Aldrich) prior to the addition of cell dissociation agent, TripLE Select using $1 \mathrm{mLcm}^{-2}$ (ThermoFisher Scientific). Cell viability was measured with the CellTiter-Blue reagent (Promega) per the manufacturer's instructions. Cells were plated in clear-bottomed 96-well plates at a density of 5000 cells per well. The inhibitors were added the following day, and cell viability was measured 24 hours later using the Synergy HT Multi-
Detection Reader (BioTek). Relative cell viability at a given inhibitor concentration was determined by comparing the fluorescence to that of DMSO treated cells.

\section{Cell migration assay}

The Oris Universal Cell Migration Assembly kit was purchased from AMS Biotechnology (Europe) Ltd and the assay was performed according to the manufacturer's instructions. Briefly, a single cell suspension $\left(5 \times 10^{4}\right.$ cells/ well/ $100 \mu \mathrm{L}$ ) was loaded into stopper-loaded wells in a 96well plate. Cells were incubated in a humidified chamber $\left(37^{\circ} \mathrm{C}, 5 \% \mathrm{CO}_{2}\right)$ for 4 hours to permit cell attachment. To start cell migration, the stoppers were removed, cells were washed with sterile PBS and fresh complete medium was added. Images were taken at various indicated time points using an Optika XDS-2 light microscope, (4x objective lens). Data were analyzed with ImageJ software (National Institute of Health, Bethesda, MA, USA). Using the xCELLigence DP device from Roche Diagnostics realtime measurements of cell migration on MRC5 cells were performed. Cells were seeded at 30,000 per well in CIMPlates 16 (Roche Diagnostics) in serum-free medium in
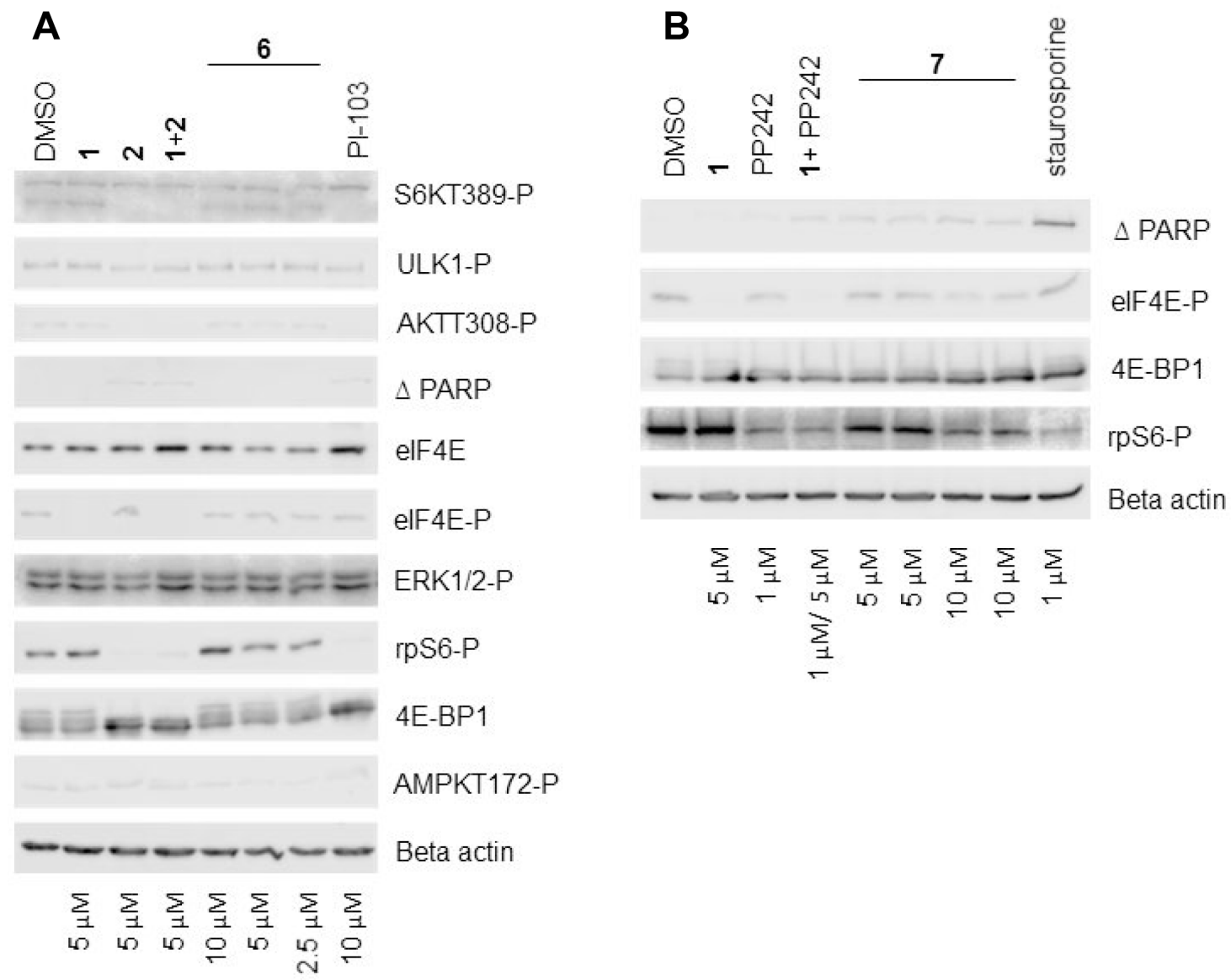

Figure 8: Characterisation of hybrid agents. (A) and (B) Western blot analysis showing the effect of different concentrations of compounds 6 and 7 respectively on various signalling molecules. MRC5 fibroblast cells were incubated with DMSO alone or with the indicated concentrations of inhibitors for 24 hours. Cellular lysates were prepared and immunoblotting was performed using $20 \mu \mathrm{g}$ of total lysate protein, as described in the Materials and Methods. 
the presence or absence of inhibitors. Full growth medium was used as a chemo-attractant in the lower chamber. As cells pass through the $8 \mu \mathrm{m}$ pores towards the chemoattractant they adhere to the underside of the filter, embedded with a gold micro-electrode. This produces an electrical impedance signal, which correlates with the number of migrating cells. Cell index is an arbitrary unit based upon the measured cell-electrode impedance derived by the software using the following calculation as described in reference [27].

\section{Immunoblotting}

Cellular lysates were prepared using lysis buffer (20 mM MOPS pH7.4, $100 \mathrm{mM} \mathrm{KCl,} 1 \mathrm{mM}$ DTT, 1 mM EDTA, $2 \mathrm{mM}$ benzamidine, $25 \mathrm{mM} \mathrm{NaF}, 5 \mu \mathrm{g} / \mathrm{mL}$ leupeptin, $10 \mathrm{mM}$ chymostatin, $1 \mu \mathrm{M}$ microcystin LR, 1 X EDTA-free protease inhibitor cocktail (Roche)). The concentration of lysate protein was determined by Bradford assay (Bio-Rad). Immunoblotting was performed using the Mini-PROTEAN Tetra Cell System (Bio-Rad) with $20 \mu \mathrm{g}$ of lysate protein. The primary antibodies used were $\beta$-actin (Abcam), cleaved PARP (Cell Signalling Technologies), AMPK(phospho-T172; Cell Signalling Technologies), eIF4E-(phospho-S209; Abcam), S6K(phospho-T389; Cell Signalling Technologies), Phospho-p44/42 MAPK (Erk1/2) (Thr202/Tyr204, Cell Signalling Technologies), 4E-BP1 (Cell Signalling Technologies), p38-MAPK (Thr180/Tyr182, Cell Signalling Technologies), PhosphoMnk1 (T197/202; Cell Signalling Technologies), Phospho-S6 Ribosomal Protein (S240/244, Cell Signalling Technologies), eIF4E (Cell Signalling Technologies), Phospho-Akt (T308, Abcam), Phospho-ULK1 (S555, Cell Signalling Technologies) and Anti-LC3B (Sigma).

\section{Flow cytometry}

Cells were seeded at $1 \times 10^{5}$ in 12 -well plates and allowed to adhere overnight. The cells were treated with the indicated concentrations of inhibitors for 24 hours. Samples were collected and fixed in $70 \%$ ethanol for 1 hour. For cell cycle analysis, fixed cells were treated with $10 \mu \mathrm{g} / \mathrm{ml}$ RNAse A for 45 minutes before the addition of $50 \mu \mathrm{g} / \mathrm{ml}$ propidium iodide for 15 minutes and then analysed by FACs using the Accuri C6 Flow Cytometer.

\section{Chemical synthesis general procedures}

All reactions were carried out in air using commercial grade starting materials, solvents, and reagents. The progress of all reactions was monitored by thin layer chromatography (TLC) using commercially available glass silica gel plates (60 $\AA$, F254). The mobile phase was generally a solvent mixture, and the visualization was undertaken using UV light. All NMR spectra were measured on a Varian NMR 500 spectrometer at $500 \mathrm{MHz}\left({ }^{1} \mathrm{H}\right)$. Chemical shifts are quoted in parts per million (ppm; \% relative to a residual solvent peak for $\left.{ }^{1} \mathrm{H}\right)$. Chromatographic purifications were undertaken using an ISCO purification unit, Combi Flash RF 75 PSI, using Biotage silica gel columns. LC-MS purity analyses were undertaken using a $5 \mu \mathrm{m} \mathrm{C18} 110 \AA$ column. The synthesis of the hybrid agents is detailed in the ESI.

\section{Supporting information}

ESI Available: [Experimental methods and NMR analysis].

\section{ACKNOWLEDGMENTS AND FUNDING}

Studentship costs to E.L. were funded by the School of Life Sciences, University of Sussex. This work was supported by the Biotechnology and Biological Sciences Research Council (UK) [grant number BB/L018209/1]. We would like to thank Professor Chris Pepper (BSMS) for assistance with the FACs analysis.

\section{CONFLICTS OF INTEREST}

No conflicts of interest.

\section{REFERENCES}

1. Chaffer CL, Weinberg RA. A perspective on cancer cell metastasis. Science. 2011; 331:1559-64.

2. Ruggero D. Translational control in cancer etiology. Cold Spring Harb Perspect Biol. 2013; 5.

3. Podo F, Buydens LM, Degani H, Hilhorst R, Klipp E, Gribbestad IS, Van Huffel S, van Laarhoven HW, Luts J, Monleon D, Postma GJ, Schneiderhan-Marra N, Santoro F, et al. Triple-negative breast cancer: present challenges and new perspectives. Mol Oncol. 2010; 4:209-29.

4. Hou J, Lam F, Proud C, Wang S. Targeting Mnks for cancer therapy. Oncotarget. 2012; 3:118-31. https://doi. org/10.18632/oncotarget.453.

5. O'Loghlen A, Gonzalez VM, Salinas M, Martin ME. Suppression of human Mnk1 by small interfering RNA increases the eukaryotic initiation factor $4 \mathrm{~F}$ activity in HEK293T cells. Proc Natl Acad Sci U S A. 2004; 578:31-5.

6. Slentz-Kesler K, Moore JT, Lombard M, Zhang J, Hollingsworth R, Weiner MP. Identification of the human Mnk2 gene (MKNK2) through protein interaction with estrogen receptor beta. Genomics. 2000; 69:63-71.

7. Beggs JE, Tian S, Jones GG, Xie J, Iadevaia V, Jenei V, Thomas G, Proud CG. The MAP kinase-interacting kinases regulate cell migration, vimentin expression and eIF4E/ CYFIP1 binding. Biochem J. 2015; 467:63-76.

8. Ueda T, Watanabe-Fukunaga R, Fukuyama H, Nagata $S$, Fukunaga R. Mnk2 and Mnk1 are essential for constitutive and inducible phosphorylation of eukaryotic initiation factor 
$4 \mathrm{E}$ but not for cell growth or development. Mol Cell Biol. 2004; 24:6539-49.

9. Diab S, Kumarasiri M, Yu M, Teo T, Proud C, Milne R, Wang S. MAP kinase-interacting kinases - emerging targets against cancer. Chem Biol. 2014; 21:441-52.

10. Stead RL, Proud CG. Rapamycin enhances eIF4E phosphorylation by activating MAP kinase-interacting kinase 2a (Mnk2a). FEBS Lett. 2013; 587:2623-8.

11. Lu C, Makala L, Wu D, Cai Y. Targeting translation: eIF4E as an emerging anticancer drug target. Expert Rev Mol Med. 2016; 18:e2.

12. Grzmil M, Huber RM, Hess D, Frank S, Hynx D, Moncayo G, Klein D, Merlo A, Hemmings BA. MNK1 pathway activity maintains protein synthesis in rapalog-treated gliomas. J Clin Invest. 2014; 124:742-54.

13. Hay N. Mnk earmarks eIF4E for cancer therapy. Proc Natl Acad Sci U S A. 2010; 107:13975-6.

14. Bhat M, Robichaud N, Hulea L, Sonenberg N, Pelletier J, Topisirovic I. Targeting the translation machinery in cancer. Nat Rev Drug Discov. 2015; 14:261-78.

15. Joshi S, Platanias LC. Mnk kinase pathway: Cellular functions and biological outcomes. World J Biol Chem. 2014; 5:321-33.

16. Ueda T, Sasaki M, Elia AJ, Chio II, Hamada K, Fukunaga R, Mak TW. Combined deficiency for MAP kinaseinteracting kinase 1 and 2 (Mnk1 and Mnk2) delays tumor development. Proc Natl Acad Sci U S A. 2010; 107:13984-90.

17. Wendel HG, Silva RL, Malina A, Mills JR, Zhu H, Ueda T, Watanabe-Fukunaga R, Fukunaga R, Teruya-Feldstein J, Pelletier J, Lowe SW. Dissecting eIF4E action in tumorigenesis. Genes \& Development. 2007; 21:3232-7.

18. Grzmil M, Morin P Jr, Lino MM, Merlo A, Frank S, Wang Y, Moncayo G, Hemmings BA. MAP kinase-interacting kinase 1 regulates SMAD2-dependent TGF-beta signaling pathway in human glioblastoma. Cancer Res. 2011; 71:2392-402.

19. Furic L, Rong L, Larsson O, Koumakpayi IH, Yoshida K, Brueschke A, Petroulakis E, Robichaud N, Pollak M, Gaboury LA, Pandolfi PP, Saad F, Sonenberg N. eIF4E phosphorylation promotes tumorigenesis and is associated with prostate cancer progression. Proc Natl Acad Sci U S A. 2010; 107:14134-9.

20. Bianchini A, Loiarro M, Bielli P, Busa R, Paronetto MP, Loreni F, Geremia R, Sette C. Phosphorylation of eIF4E by MNKs supports protein synthesis, cell cycle progression and proliferation in prostate cancer cells. Carcinogenesis. 2008; 29:2279-88.

21. Li Z, Sun Y, Qu M, Wan H, Cai F, Zhang P. Inhibiting the MNK-eIF4E-beta-catenin axis increases the responsiveness of aggressive breast cancer cells to chemotherapy. Oncotarget. 2017; 8:2906-15. https://doi.org/10.18632/ oncotarget.13772.

22. Fan QW, Knight ZA, Goldenberg DD, Yu W, Mostov KE, Stokoe D, Shokat KM, Weiss WA. A dual PI3 kinase/mTOR inhibitor reveals emergent efficacy in glioma. Cancer Cell. 2006; 9:341-9.

23. Bansal Y, Silakari O. Multifunctional compounds: smart molecules for multifactorial diseases. Eur J Med Chem. $2014 ; 76: 31-42$.

24. Liu Y, Sun L, Su X, Guo S. Inhibition of eukaryotic initiation factor $4 \mathrm{E}$ phosphorylation by cercosporamide selectively suppresses angiogenesis, growth and survival of human hepatocellular carcinoma. Biomed Pharmacother. 2016; 84:237-43.

25. Konicek BW, Stephens JR, McNulty AM, Robichaud N, Peery RB, Dumstorf CA, Dowless MS, Iversen PW, Parsons S, Ellis KE, McCann DJ, Pelletier J, Furic L, et al. Therapeutic inhibition of MAP kinase interacting kinase blocks eukaryotic initiation factor 4E phosphorylation and suppresses outgrowth of experimental lung metastases. Cancer Res. 2011; 71:1849-57.

26. Teo T, Yu M, Yang Y, Gillam T, Lam F, Sykes MJ, Wang S. Pharmacologic co-inhibition of Mnks and mTORC1 synergistically suppresses proliferation and perturbs cell cycle progression in blast crisis-chronic myeloid leukemia cells. Cancer Lett. 2015; 357:612-23.

27. Sun M, Fu H, Cheng H, Cao Q, Zhao Y, Mou X, Zhang X, Liu X, Ke Y. A dynamic real-time method for monitoring epithelial barrier function in vitro. Anal Biochem. 2012; 425:96-103.

28. Hollestelle A, Nagel JH, Smid M, Lam S, Elstrodt F, Wasielewski M, Ng SS, French PJ, Peeters JK, Rozendaal MJ, Riaz M, Koopman DG, Ten Hagen TL, et al. Di stinct gene mutation profiles among luminal-type and basal-type breast cancer cell lines. Breast Cancer Res Treat. 2010; 121:53-64.

29. O'Connor PM, Jackman J, Bae I, Myers TG, Fan S, Mutoh M, Scudiero DA, Monks A, Sausville EA, Weinstein JN, Friend S, Fornace AJ Jr, Kohn KW, et al. Characterization of the p53 tumor suppressor pathway in cell lines of the National Cancer Institute anticancer drug screen and correlations with the growth-inhibitory potency of 123 anticancer agents. Cancer Res. 1997; 57:4285-300.

30. Teo T, Yang Y, Yu M, Basnet SK, Gillam T, Hou J, Schmid RM, Kumarasiri M, Diab S, Albrecht H, Sykes MJ, Wang S. An integrated approach for discovery of highly potent and selective Mnk inhibitors: Screening, synthesis and SAR analysis. Eur J Med Chem. 2015; 103:539-50.

31. Folkes AJ, Ahmadi K, Alderton WK, Alix S, Baker SJ, Box G, Chuckowree IS, Clarke PA, Depledge P, Eccles SA, Friedman LS, Hayes A, Hancox TC, et al. The identification of 2-(1H-indazol-4-yl)-6-(4-methanesulfonyl-piperazin1-ylmethyl)-4-morpholin-4-yl-t hieno[3,2-d]pyrimidine (GDC-0941) as a potent, selective, orally bioavailable inhibitor of class I PI3 kinase for the treatment of cancer. J Med Chem. 2008; 51:5522-32.

32. Hemmings BA, Restuccia DF. The PI3K-PKB/Akt pathway. Cold Spring Harb Perspect Biol. 2015; 7. 
33. Zheng Y, Jiang Y. mTOR Inhibitors at a Glance. Mol Cell Pharmacol. 2015; 7:15-20.

34. Apsel B, Blair JA, Gonzalez B, Nazif TM, Feldman ME, Aizenstein B, Hoffman R, Williams RL, Shokat KM, Knight ZA. Targeted polypharmacology: discovery of dual inhibitors of tyrosine and phosphoinositide kinases. Nat Chem Biol. 2008; 4:691-9.

35. Robichaud N, del Rincon SV, Huor B, Alain T, Petruccelli LA, Hearnden J, Goncalves C, Grotegut S, Spruck CH, Furic L, Larsson O, Muller WJ, Miller WH, et al. Phosphorylation of eIF4E promotes EMT and metastasis via translational control of SNAIL and MMP-3. Oncogene. 2015; 34:2032-42.

36. Levin EG. Cancer therapy through control of cell migration. Curr Cancer Drug Targets. 2005; 5:505-18.

37. Brown MC, Gromeier M. MNK inversely regulates TELO2 vs. DEPTOR to control mTORC1 signaling. Mol Cell Oncol. 2017; 4:e1306010.

38. Vassilev LT. Cell cycle synchronization at the G2/M phase border by reversible inhibition of CDK1. Cell Cycle. 2006; 5:2555-6.

39. Coles SJG, Gale PA. Changing and challenging times for service crystallography. Chem Sci. 2012; 3:683-9.

40. Gediya LK, Khandelwal A, Patel J, Belosay A, Sabnis G, Mehta J, Purushottamachar P, Njar VC. Design, synthesis, and evaluation of novel mutual prodrugs (hybrid drugs) of all-trans-retinoic acid and histone deacetylase inhibitors with enhanced anticancer activities in breast and prostate cancer cells in vitro. J Med Chem. 2008; 51:3895-904.

41. Cai X, Zhai HX, Wang J, Forrester J, Qu H, Yin L, Lai CJ, Bao R, Qian C. Discovery of 7-(4-(3-ethynylphenylamino)7-methoxyquinazolin-6-yloxy)-N-hydroxyheptanamide
(CUDc-101) as a potent multi-acting HDAC, EGFR, and HER2 inhibitor for the treatment of cancer. J Med Chem. 2010; 53:2000-9.

42. Woo LW, Bubert C, Purohit A, Potter BV. Hybrid dual aromatase-steroid sulfatase inhibitors with exquisite picomolar inhibitory activity. ACS Med Chem Lett. 2011; 2:243-7.

43. Patel H, Chuckowree I, Coxhead P, Guille M, Wang M, Zuckermann A, Williams RSB, Librizzi M, Paranal RM, Bradner JE, Spencer J. Synthesis of hybrid anticancer agents based on kinase and histone deacetylase inhibitors. MedChemComm. 2014; 5:1829-33.

44. De Lera AR, Ganesan A. Epigenetic polypharmacology: from combination therapy to multitargeted drugs. Clin Epigenetics. 2016; 8:105.

45. Fortin S, Berube G. Advances in the development of hybrid anticancer drugs. Expert Opin Drug Discov. 2013; 8:1029-47.

46. Berube G. An overview of molecular hybrids in drug discovery. Expert Opin Drug Discov. 2016; 11:281-305.

47. Nepali K, Sharma S, Kumar D, Budhiraja A, Dhar KL. Anticancer hybrids--a patent survey. Recent Pat Anticancer Drug Discov. 2014; 9:303-39.

48. Rodrik-Outmezguine VS, Okaniwa M, Yao Z, Novotny CJ, McWhirter C, Banaji A, Won H, Wong W, Berger M, de Stanchina E, Barratt DG, Cosulich S, Klinowska T, et al. Overcoming mTOR resistance mutations with a newgeneration mTOR inhibitor. Nature. 2016; 534:272-6.

49. Lineham E, Spencer J, Morley SJ. Dual abrogation of MNK and mTOR: a novel therapeutic approach for the treatment of aggressive cancers. Future Med Chem. 2017; 9:1539-1555. 